Case Reports in
Gastroenterology
Case Rep Gastroenterol 2020;14:675-682

DOI: 10.1159/000509499

Published online: December 11, 2020

(C) 2020 The Author(s)

Published by S. Karger AG, Basel

www.karger.com/crg

This article is licensed under the Creative Commons Attribution-NonCommercial 4.0 International License (CC BY-NC) (http://www.karger.com/Services/OpenAccessLicense). Usage and distribution for commercial purposes requires written permission.

\title{
Laparoscopy-Assisted Repair for Intersigmoid Hernia
}

\author{
Yuichi Nakaseko Koichiro Haruki Kai Neki Ryosuke Hashizume \\ Ken Eto Katsuhiko Yanaga \\ Departments of Surgery, The Jikei University School of Medicine, Tokyo, Japan
}

\section{Keywords}

Internal hernia $\cdot$ Intersigmoid hernia $\cdot$ Laparoscope

\begin{abstract}
Intersigmoid hernia is a rare clinical entity. Only 6 cases of laparoscopic repair for intersigmoid hernia have been reported since 1977 . We herein report such a case, which was successfully diagnosed preoperatively and treated with laparoscopic repair. A 50-year-old man with a chief complaint of abdominal pain and vomiting was admitted for the treatment of small bowel obstruction. The patient had no history of abdominal surgery. Computed tomography showed a dilated small bowel and a closed loop of small bowel dorsal to the sigmoid colon and the sigmoid mesocolon. With a diagnosis of an incarcerated internal hernia, the patient underwent emergency laparoscopy-assisted surgery. Laparoscopy showed that the ileum had herniated into the intersigmoid fossa, and therefore the patient was diagnosed with an intersigmoid hernia. Because bowel ischemia was not observed, we reduced the incarcerated small bowel, and the hernial defect was widely opened. After operation, the patient developed ileus and was treated with transnasal ileus tube. Thereafter, the patient made a satisfactory recovery and was discharged on postoperative day 21. The patient is in good general condition without ileus 42 months postoperatively.




\section{Case Reports in Gastroenterology}

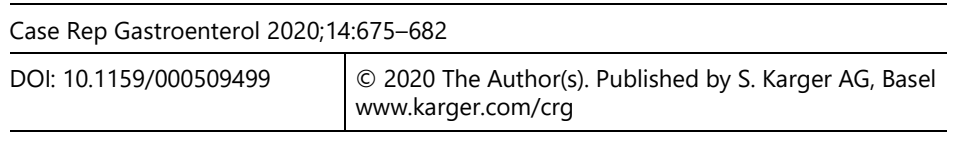

Nakaseko et al.: Laparoscopy-Assisted Repair for Intersigmoid Hernia

\section{Introduction}

An internal hernia is defined as a protrusion of a viscus through a normal or abnormal peritoneal or mesenteric aperture within the abdominal and pelvic cavity. It is a rare cause of small bowel obstruction.

Internal hernias are uncommon and very rarely involve the sigmoid mesocolon. Furthermore, intersigmoid hernia is extremely rare, which is a subtype of sigmoid mesocolon hernia. The preoperative diagnosis of intersigmoid hernia is difficult, and verification of the diagnosis usually requires surgery $[1,2]$. Moreover, there have been few reports on laparoscopic repair of intersigmoid hernia [3-7]. We herein report a case of intersigmoid hernia, which was successfully diagnosed preoperatively and treated with laparoscopic repair.

\section{Case Report}

A 50-year-old man, with a chief complaint of abdominal pain and vomiting, was admitted for the treatment of small bowel obstruction. The patient had no history of abdominal surgery. Physical examination revealed distension and tenderness in the entire abdomen without any muscular defense. Laboratory data showed elevated peripheral white blood cell count of $14,000 / \mathrm{mm}^{3}$ and slightly increased C-reactive protein level of $0.72 \mathrm{mg} / \mathrm{dL}$, while creatine kinase and lactate were within normal limits. Computed tomography (CT) of the abdominal cavity demonstrated a dilated small bowel and a closed loop of small bowel dorsal to the sigmoid colon and mesocolon (Fig. 1a, b). The patient was diagnosed to have an incarcerated internal hernia and underwent emergency laparoscopy-assisted surgery. Laparoscopy showed that the ileum had herniated into the intersigmoid fossa (Fig. 2a) and, therefore, the diagnosis of intersigmoid hernia was confirmed. The defect in the mesosigmoid was approximately $2 \mathrm{~cm}$ in diameter, through which the small bowel $(20 \mathrm{~cm}$ in length) was incarcerated. No ischemic lesion was observed in the incarcerated small bowel (Fig. 2b). The intersigmoid fossa was widely opened (Fig. 2c) and incidental small bowel injury was repaired extracorporeally through a small umbilical wound extension of $4 \mathrm{~cm}$ (Fig. 3). After operation, the patient developed ileus and was treated with transnasal ileus tube. Thereafter, the patient made a satisfactory recovery and was discharged on postoperative day 21 . The patient is in good general condition without ileus 36 months postoperatively.

\section{Discussion/Conclusion}

Sigmoid mesocolon hernias, including intersigmoid hernia, intermesosigmoid hernia, and transmesosigmoid hernia, account for approximately 4-8\% of internal hernias [8, 9]. Intersigmoid hernia is an internal abdominal hernia that occurs in the intersigmoid fossa, located on the lateral aspect of the connection with the sigmoid mesocolon [10]. The intersigmoid fossa is a peritoneal pocket formed between two adjacent sigmoid segments and their mesentery (Fig. 4). Intersigmoid hernia is defined as the abnormal passage of abdominal contents 


\section{Case Reports in Gastroenterology}

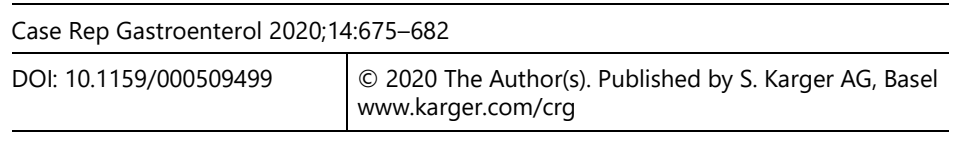

Nakaseko et al.: Laparoscopy-Assisted Repair for Intersigmoid Hernia

through this orifice [11]. The treatment of sigmoid mesocolon hernias is either a reduction or a resection of the herniated intestine with closure of the defect. Several reports suggest the usefulness of laparoscopic abdominal surgery for both diagnosis and treatment $[12,13]$.

Recently, laparoscopic surgery has been broadly performed for small-bowel obstruction. Laparoscopic surgery provides not only high diagnostic value but also minimal invasiveness in comparison with open surgery. Since intersigmoid hernia has few specific clinical findings or symptoms, it is difficult to be diagnosed preoperatively. Therefore, laparoscopic surgery would be recommended to get further diagnosis of small-bowel obstruction due to internal hernia, as it is not rare for internal hernia to be diagnosed after laparotomy [3]. Additionally, sufficient decompression by long-tube insertion is necessary for safe anastomosis as well as reliable reconstruction [5]. Insufficient surgical space due to inadequate decompression results in more frequent intestinal damage because the intestinal wall is fragile as a result of intestinal edema [6].

Six cases of laparoscopic surgery for an intersigmoid hernia have been reported since 1977 in the English literature; details of 7 patients, including the present case, are summarized in Table 1 [3-7]. Among the patients, the mean age was 54.9 years with a range from 26 to 86 years; 5 of them were male and 2 of them ware female. All of them had no history of abdominal surgery. The interval between admission to surgery varies from $2 \mathrm{~h}$ to 16 days. As for method of hernia orifice repair, 3 cases were simple closure and 4 cases were widely opened. In the present case, the patient was diagnosed with sigmoid mesocolon hernia by CT, resulting in a shorter interval from admission to surgery than that of the other cases. We performed dissection of the intersigmoid fossa and then found incidental injury of the dilated small bowel, for which repair was needed. Therefore, the injury might have been avoided if an ileus tube had been inserted to decompress the small bowel prior to laparoscopic surgery.

We reported a case of intersigmoid hernia, which was successfully diagnosed preoperatively. Laparoscopic surgery is minimally invasive and useful for both diagnosis and treatment of intersigmoid hernia.

\section{Statement of Ethics}

All procedures followed were in accordance with the ethical standards of the responsible committee on human experimentation (institutional and national) and with the Helsinki Declaration of 1975, as revised in 2008. Informed consent was obtained from the patient for being included in the study.

\section{Conflict of Interest Statement}

The authors have no conflicts of interest to declare.

\section{Karger'}




\section{Case Reports in Gastroenterology}

\section{Funding Sources}

The authors received no funding or grant support for this study.

\section{Author Contributions}

The study conception and design were made by Y. Nakaseko and K. Haruki. Acquisition of data was done by Y. Nakaseko, K. Neki, R. Hashizume, and K. Eto. Drafting of the manuscript and illustration were done by Y. Nakaseko. Critical revision of the manuscript was done by K. Haruki and K. Yanaga.

\section{References}

1 Fan HP, Yang AD, Chang YJ, Juan CW, Wu HP. Clinical spectrum of internal hernia: a surgical emergency. Surg Today. 2008;38(10):899-904.

2 Puri V, Bertellotti RP, Garg N, Fitzgibbons RJ Jr. Intramesosigmoid hernia: a rare type of congenital internal hernia. Hernia. 2007 Oct;11(5):463-5.

3 Watanabe T, Wada H, Sato M, Miyaki Y, Shiiya N. Single-incision laparoscopic surgery for intersigmoid hernia. Case Rep Surg. 2014;2014:589649.

4 Kumagai K, Yoshioka M, Iida M, Kudoh K, Uchinami H, Watanabe T, et al. Usefulness of Oblique Multiplanar Images on Multi-Detector Computed Tomography for Diagnosing Intersigmoid Hernia. Visc Med. 2016 Dec;32(6):437-40.

5 Shibuya N, Ishizuka M, Iwasaki Y, Takagi K, Nagata H, Aoki T, et al. Usefulness of a laparoscopic approach for treatment of small-bowel obstruction due to intersigmoid hernia: a case report. Surg Case Rep. 2017 Dec;3(1):22.

6 Kayano H, Nomura E, Kuramoto T, Yatabe K, Yoshii H, Yokoyama D, et al. Two cases of laparoscopic diagnosis and treatment of intersigmoid hernia. Tokai J Exp Clin Med. 2017 Jul;42(2):109-14.

7 Tatsuta K, Miyazaki S, Nishiwaki Y. Emergency laparoscopic approach without sufficient preoperative decompression for intersigmoid hernia: A case report. Int J Surg Case Rep. 2019;64:54-7.

8 Benson JR, Killen DA. Internal hernias involving the sigmoid mesocolon. Ann Surg. 1964 Mar;159(3):382-4.

9 Mathieu D, Luciani A; GERMAD Group. Internal abdominal herniations. AJR Am J Roentgenol. 2004 Aug;183(2):397-404.

10 Takeyama N, Gokan T, Ohgiya Y, Satoh S, Hashizume T, Hataya K, et al. CT of internal hernias. Radiographics. 2005 Jul-Aug;25(4):997-1015.

11 Harrison OJ, Sharma RD, Niayesh MH. Early intervention in intersigmoid hernia may prevent bowel resection-A case report. Int J Surg Case Rep. 2011;2(8):282-4.

12 Nihon-Yanagi Y, Ooshiro M, Osamura A, Takagi R, Moriyama A, Urita T, et al. Intersigmoid hernia: report of a case. Surg Today. 2010;40(2):171-5.

13 Van der Mieren G, de Gheldere C, Vanclooster P. Transmesosigmoid hernia: report of a case and review of the literature. Acta Chir Belg. 2005 Nov-Dec;105(6):653-5. 


\section{Case Reports in Gastroenterology}
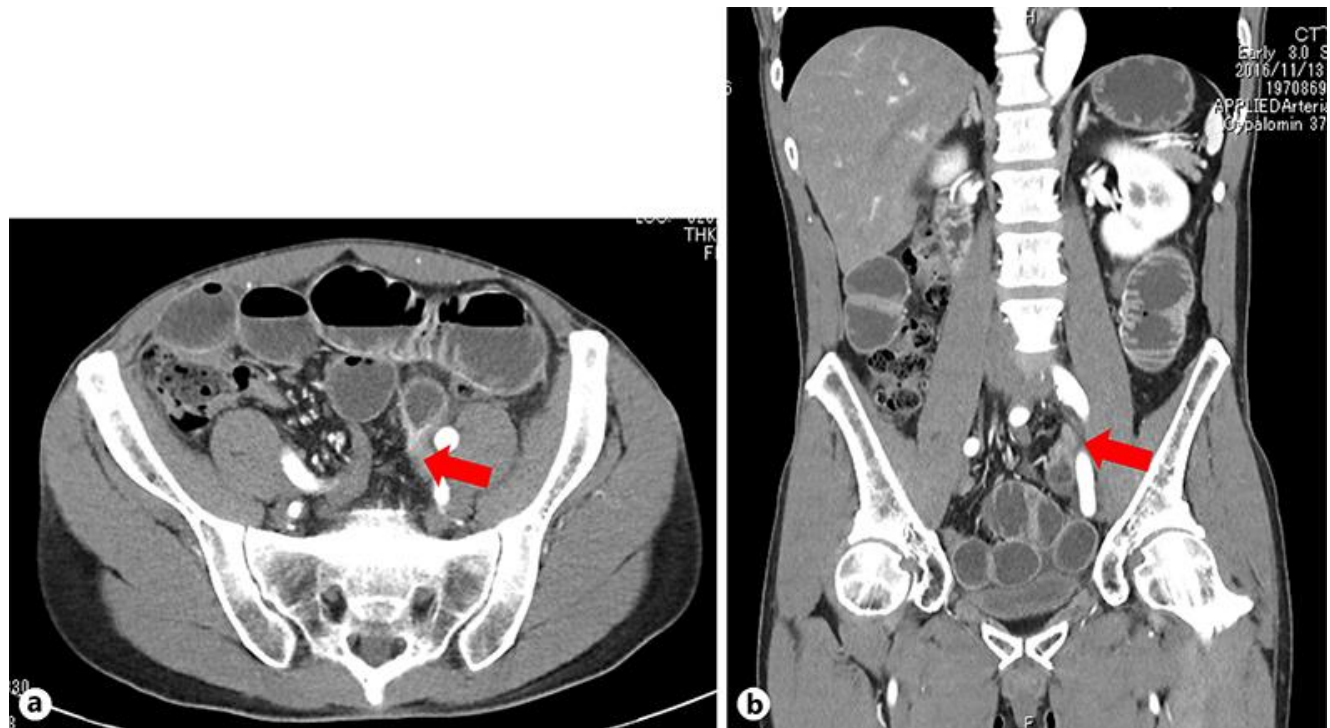

Fig. 1. Computed tomography showed an extensively dilated small bowel and a closed loop of small bowel in the mesosigmoid (arrow) (a).b Obstructive small intestine behind the mesentery of the sigmoid colon (arrow). 


\section{Case Reports in Gastroenterology}

Case Rep Gastroenterol 2020;14:675-682
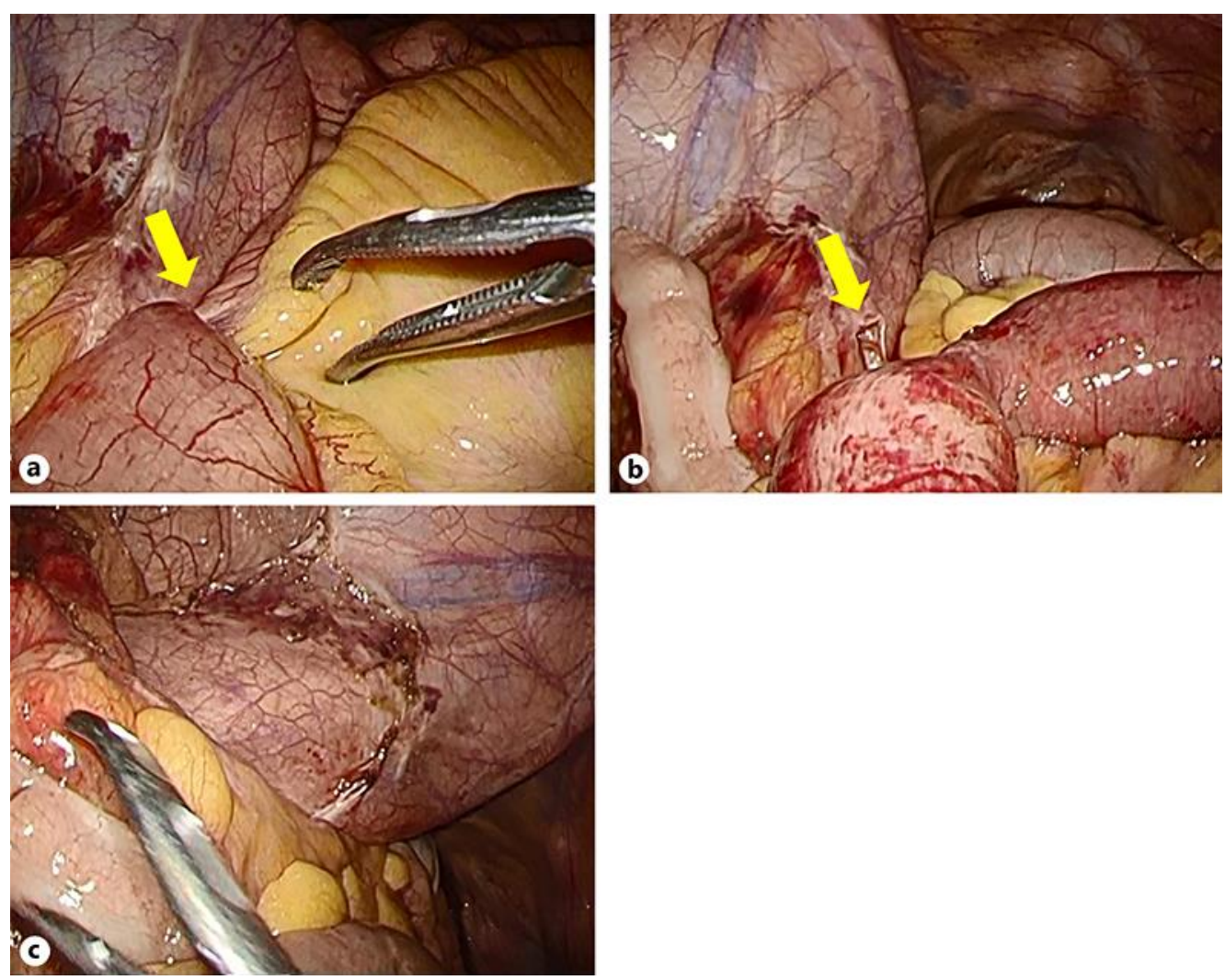

(c) 2020 The Author(s). Published by S. Karger AG, Basel www.karger.com/crg

Nakaseko et al.: Laparoscopy-Assisted Repair for Intersigmoid Hernia

Fig. 2. Intraoperative findings. a Laparoscopy showed that the small intestine had herniated into the intersigmoid fossa (arrow). b The hernia orifice was $2 \mathrm{~cm}$ in diameter (arrow). c The hernia orifice was dissected and widely opened. 
Case Reports in

Gastroenterology
Case Rep Gastroenterol 2020;14:675-682

(c) 2020 The Author(s). Published by S. Karger AG, Basel www.karger.com/crg

Nakaseko et al.: Laparoscopy-Assisted Repair for Intersigmoid Hernia

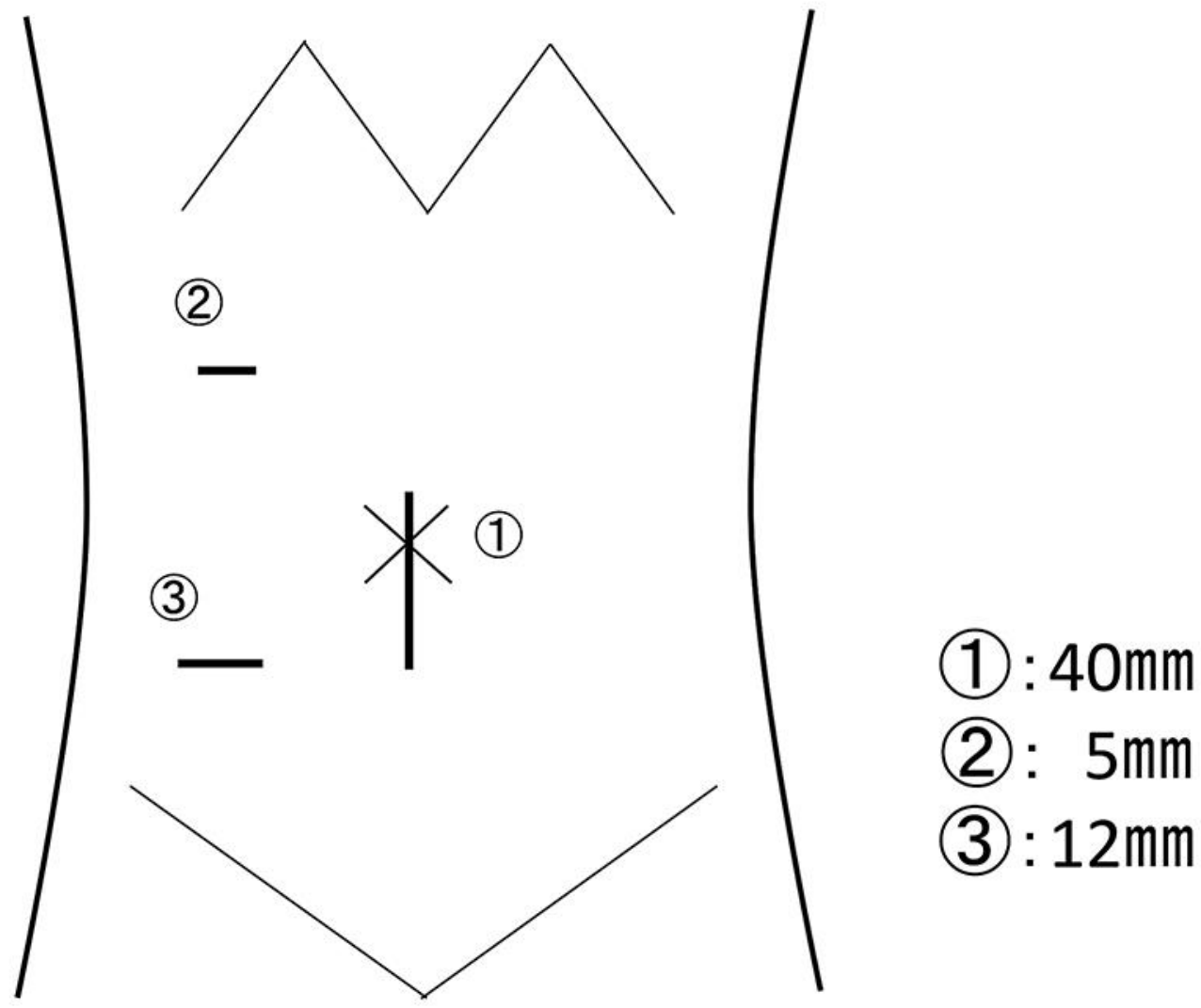

Fig. 3. Position and size of trocars. Small incision was added to the umbilicus to repair the injured small bowel. 


\section{Case Reports in Gastroenterology}

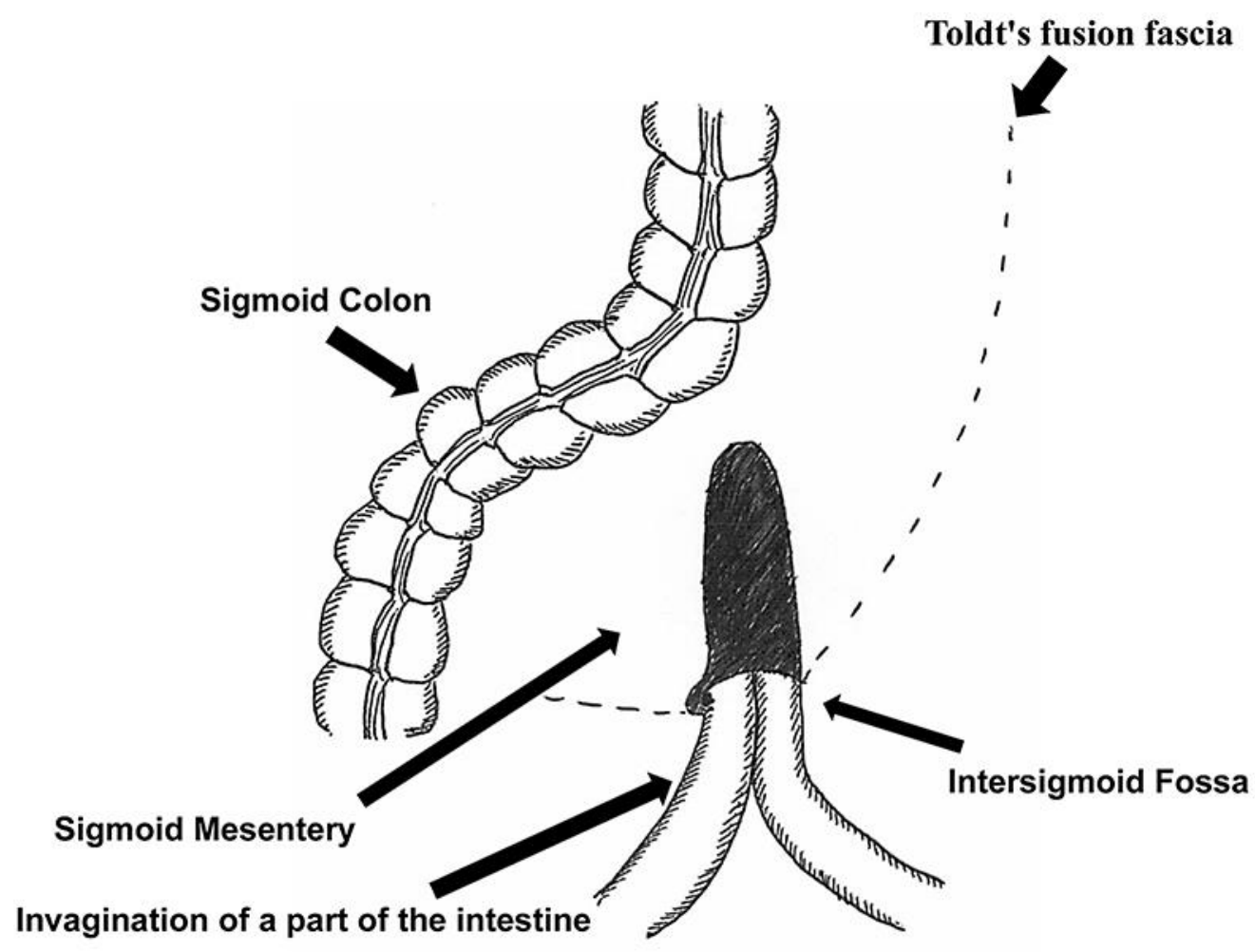

Fig. 4. The location of the intersigmoid fossa at the base of the sigmoid mesentery.

Table 1. Previously reported cases of intersigmoid hernias treated with laparoscopic surgery

\begin{tabular}{|c|c|c|c|c|c|c|c|c|c|c|c|}
\hline Case & $\begin{array}{l}\text { First author } \\
\text { [ref.] }\end{array}$ & Year & $\begin{array}{l}\text { Age, } \\
\text { years }\end{array}$ & Gender & $\begin{array}{l}\text { Interval from } \\
\text { admission to } \\
\text { surgery }\end{array}$ & $\begin{array}{l}\text { Prior } \\
\text { abdominal } \\
\text { surgery }\end{array}$ & $\begin{array}{l}\text { Operation } \\
\text { time, min }\end{array}$ & $\begin{array}{l}\text { Size of } \\
\text { hernia } \\
\text { orifice, cm }\end{array}$ & $\begin{array}{l}\text { Bowel } \\
\text { resection }\end{array}$ & Type of repair & $\begin{array}{l}\text { Postoperative } \\
\text { hospital stay, } \\
\text { days }\end{array}$ \\
\hline 1 & Watanabe [3] & 2014 & 26 & Male & 7 days & No & N/A & 3 & No & Simple closure & 5 \\
\hline 2 & Kumagai [4] & 2016 & 82 & Male & 14 days & No & $\mathrm{N} / \mathrm{A}$ & N/A & No & Widely open & $\mathrm{N} / \mathrm{A}$ \\
\hline 3 & Shibuya [5] & 2017 & 45 & Female & 14 days & No & 108 & N/A & No & Widely open & 8 \\
\hline 4 & Kayano [6] & 2017 & 42 & Female & 16 days & No & 139 & $\mathrm{~N} / \mathrm{A}$ & Yes & Simple closure & 7 \\
\hline 5 & Kayano [6] & 2017 & 53 & Male & 11 days & No & 84 & N/A & No & Simple closure & 8 \\
\hline 6 & Tatsuta [7] & 2019 & 86 & Male & A few days & No & 86 & $\mathrm{~N} / \mathrm{A}$ & No & Widely open & $\mathrm{N} / \mathrm{A}$ \\
\hline 7 & Current case & 2019 & 50 & Male & 2 hours & No & 92 & 2 & No & Widely open & 21 \\
\hline
\end{tabular}

